\title{
Emir Rodríguez Monegal contesta a Gerald Martin
}

No hay peor crítico que el que no quiere leer. El Sr. Gerald Martin escribe doce páginas para refutar un artículo mío sobre Asturias (de siete páginas y media), y empieza por tergiversar cada una de las palabras que yo empleo. Baste comparar lo que escribí con lo que me hace decir el Sr. Martin. Veamos.

Seguin el Sr. Martin:

"...el señor Rodríguez Monegal afirma que la década decisiva de Asturias comienza en 1946, año en que publica El Señor Presidente, y termina en 1956, después de la publicación de Hombres de maíz; Viento fuerte, El papa verde y Week end en Guatemald. Pasa por alto las Leyendas de Guatemala (1930), porque "Io mejor de las Leyendas resultará incorporado a libros posteriores", con lo que volvemos al compartimento de contenidos e influencias literarias como si fueran entidades con peso $y$ medida. Ahora bien, es de suponer que cuando el señor Rodríguez Monegal se refiere a los logros literarios de Miguel Angel Asturias en esa década, nos está hablando de sus logros artísticos, ya que el verdadero reconocimiento crítico de ellos no le fue conferido a Asturias sino hasta mucho más tarde, y siendo así tenemos que subrayar de nuevo nuestra inconformidad. Cuando el señor Rodríguez Monegal acepta, precisamente en el artículo que nos ocupa, que El Señor Presidente ya estaba escrito en forma definitiva en 1932, ¿qué sentido tiene referirse a la década 1946-56 como la de la verdadera actividad creadora?"

Pero lo que yo había escrito no es exactamente lo mismo que me hace decir el Sr. Martin. Transcribo el párrafo que él pretende resumir y analizar para que se vea la diferencia: (Subrayo las palabras clave, sobre las que parece no detenerse el Sr. Martin).

"La fama de Miguel Angel Asturias, desde la publicación de El Señor 
Presidente, en 1946, hasta el Premio Nóbel de Literatura 1967, ha sufrido curiosas alternativas que convendría examinar, así sea brevemente. Un primer período de éxito corresponde a la década 1946/1956. Entre esas dos fechas, Asturias no sólo da a conocer su primera novela importante sino que, también, produce una serie de relatos y hasta una novela. río qué cuentan entre lo más destacado que se escribe entonces en América Latina".

Es evidente, para cualquiera que lea sin anteojeras y prejuicios, que me estoy refiriendo a su fama, a la publicación y difusión de su obra, y al juicio que ésta merece en su época. El Sr. Martin, en cambio, me hace hablar de "logros literarios" y de "logros artísticos", porque busca determinar la contradicción de mi pensamiento crítico. La tarea es inátil. $\mathrm{Si}$ en vez de imaginarse lo que no he escrito, se toma el trabajo de leer y entender lo que sí he escrito, verá que la mitad de su refutación es superflua.

Queda la otra mitad. En ella se me acusa de tener "motivos personales y profesionales" para no reconocer la grandeza de Asturias; de "diletan. tismo"; de "reacción mezquina" ante su obra; y se concluye afirmando que Asturias es "un escritor que nunca le (me) ha interesado profesionalmente".

La razón de esta maldad mía está en la página 515: si excluyo a Asturias de la lista de nuevos novelistas. latinoamericanos, es porque me interesa reservarme el papjel de precursor de dicha novela, y negárselo a Asturias. Esta hipótesis del Sr. Martin no está apoyada en ninguna cita mía. Es una deducción crítica suya. Sería fácil refutarla con algún texto que sí he escrito y publicado bajo mi nombre. Por ejemplo éste, de la revista Mundo Nuevo (No. 17, París, noviembre 1967):

"A la zaga de los maestrơs de las cuatro primeras décadas de este siglo $(\ldots)$, la novela latinoamericana ha producido en los últimos treinta años por lo menos cuatro promociones perfectamente identificables. $\mathrm{La}$ primera estaría representada, entre otros, por gente como Miguel Angel Asturias, Jorge Luis Borges, Alejo Carpentier, Agustín Yáñez y Leopoldo Marechal. Ellos, y sus pares, son los grandes renovadores del género narrativo en este siglo."

$\mathrm{El}$ artículo se llama, naturalmente, Los nuevos novelistas, y está en las páginas 19-24.

Aunque el Sr. Martin escribe desde la Universidad de Edimburgo (ciudad de clima fresco, si las hay), la temperatura de su artículo sugiere las delicias del trópico. Es un artículo truculento, lleno de toda clase de insinuaciones y redolente de una pedantería académica que sienta mal 
en quien no tiene la humildad de leer bien los textos de un crítico al que pretende refutar. Le aconsejo que se tome una ducha escocesa la próxima vez que quiera escribir en contra de alguien. Después de la ducha, bien abrigado en un ropón, y con un buen fueguito cerca, debe ponerse a leer con todo cuidado, el material crítico relevante. Entonces podrá descubrir que, además de haber escrito siete páginas y media sobre Asturias, he escrito (en Marcha, de Montevideo, 1946) una de las primeras reseñas entusiásticas de El Señor Presidente; que en 1952, en un artículo panorámico sobre la nueva novela latinoamericana, publicado en el mismo semanario, ya destaqué el valor renovador dentro de dicha literatura, de la obra de Asturias y, en particular, de Hombres de maíz; que en las páginas literarias del mismo semanario anticipé una de las mejores narraciones de Week-end en Guatemala, "La Galla"; que nunca he negado a Asturias la eminencia, el pan y la sal.

Lo que he dicho, y repito ahora, es que su gran contribución a la no. vela latinoamericana está en su primera época, que El Señor Presidente en una obra híbrida, que Hombres de maiz es su obra maestra, que Mulata de tal es reiterativa, que la trilogía bananera es mala literatura. Si el Sr. Martin quiere discrepar de estos juicios no necesita atribuirme intenciones que no tengo y que son inverificables. Analice él profunda y eruditamente la obra de Asturias, publique sus conclusiones y entonces, con los textos en la mano, será posible ver si su crítica es o no válida. Por ahora lo que se ve del Sr. Martin es que practica la crítica de las intenciones imaginarias, de las citas tergiversadas, del tropicalismo estilístico. Como dijo cierta vez un polemista británico al que tiraron un vaso de vino durante una discusión literaria:

-Caballero, esto es una digresión. Espero su argumento.

Yale University

Emir Rodríguez Monegal 
